\title{
Belgeo
}

Revue belge de géographie

4 | 2004

Maritime and port economic geography

\section{Bouguerra M.L., Les batailles de l'eau : pour un bien commun de l'humanité}

Paris, Enjeux Planète, 240 p.

\section{Pierre Cornut}

\section{OpenEdition}

\section{Journals}

Édition électronique

URL : http://journals.openedition.org/belgeo/13455

ISSN : 2294-9135

\section{Éditeur :}

National Committee of Geography of Belgium, Société Royale Belge de Géographie

\section{Édition imprimée}

Date de publication : 31 décembre 2004

Pagination : 497-508

ISSN : 1377-2368

\section{Référence électronique}

Pierre Cornut, « Bouguerra M.L., Les batailles de l'eau : pour un bien commun de l'humanité », Belgeo [En ligne], 4 | 2004, mis en ligne le 15 septembre 2013, consulté le 22 septembre 2020. URL : http:// journals.openedition.org/belgeo/13455

Ce document a été généré automatiquement le 22 septembre 2020.

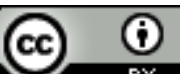

Belgeo est mis à disposition selon les termes de la licence Creative Commons Attribution 4.0 International. 


\title{
Bouguerra M.L., Les batailles de l'eau : pour un bien commun de l'humanité
}

\author{
Paris, Enjeux Planète, 240 p.
}

\section{Pierre Cornut}

\section{RÉFÉRENCE}

Bouguerra M.L., Les batailles de l'eau : pour un bien commun de l'humanité, Paris, Enjeux Planète, 2003, $240 \mathrm{p}$.

1 Une fois n'est pas coutume, cet ouvrage n'est pas un "pur " produit géographique. Néanmoins, tant son approche que la diversité des cas évoqués le rendent digne d'intérêt pour tout géographe s'intéressant à la gestion des ressources naturelles par les sociétés humaines. Il n'est pas uniquement question de «batailles" dans cet ouvrage qui tente de cerner, avec modestie, le problème de la gestion de l'eau dans sa globalité. L'auteur fait le point sur la réalité de la «crise de l'eau» et sur ce qu'elle implique pour les sociétés, tant du point de vue de la solidarité entre les hommes que de leurs rapports avec la nature. Très abordable et abondamment illustré, l'ouvrage fournit des clés de lecture pertinentes à celui qui s'intéresse au sujet.

2 La première partie, peu banale dans ce genre d'ouvrage, débute par une description des différentes symboliques de l'eau dans de nombreuses cultures et sociétés, qui nous permet d'apprécier l'importance cruciale de l'eau dans notre «humanité ». Ensuite, il fait le point sur les recherches sur l'eau et montre combien le comportement et la nature physico-chimique d'aqua simplex, ainsi que son rôle dans les écosystèmes, ne cessent de surprendre les scientifiques et faire l'objet de recherches toujours plus poussées.

Dans la seconde partie, les chapitres 3 à 6 , en abordant la répartition inégale de la ressource hydrique et les conflits géostratégiques qui y sont liés, nous rappellent avec moult exemples que l'eau, en tant que ressource indispensable à la survie, est l'enjeu de 
rapports de force et de luttes de pouvoir indissociables des problèmes d'inégalités sociales et géographiques.

Y a-t-il une réelle "crise de l'eau " au niveau mondial, s'interroge l'auteur dans le chapitre 7, ou bien est-ce une production sociale fabriquée par de puissants lobbies qui usent et abusent du concept à leur profit ? La réponse n'est pas tranchée, probablement parce que les deux processus se côtoient sans s'exclure. Certes, les exemples de crises locales se multiplient de par le monde, au point d'envisager une crise globale. De plus, ces crises sont essentiellement liées au développement économique "à l'occidentale ", à une mutation des modes de gestion des ressources depuis les méthodes traditionnelles vers une consommation et une pollution incontrôlées. Néanmoins, l'auteur montre bien, surtout dans le chapitre suivant, que la multiplication de ces crises a permis l'extraordinaire développement d'un nouveau secteur industriel capitaliste, celui de la gestion de l'eau. C'est un portrait sans concession et abondamment illustré de la privatisation de l'eau qui nous est alors livré. Quel que soit l'endroit du monde, l'appropriation des infrastructures et/ou des ressources, voire la simple délégation de service à des entreprises, se révèlent toujours catastrophiques pour les plus démunis.

5 La troisième partie, non moins intéressante que les précédentes, décrit les relations entre l'eau et la santé humaine ainsi que les pollutions multiformes de l'eau. Ici aussi, que ce soit à propos de l'eau en bouteille ou de la pollution industrielle des aquifères, ce sont bien les rapports de force socio-économiques qui règlent le jeu.

On peut regretter le chapitre sur les barrages qui, d'une part, est étrangement situé dans la partie contenant les conclusions éthiques de l'auteur, et d'autre part, prend une position très partisane ne soulignant pas assez les aspects positifs de ces ouvrages hydrauliques.

7 L'épilogue, très humaniste mais aussi un peu trop naïvement optimiste, nous montre qu'il y a des raisons d'espérer, et explique quels sont les moyens d'atteindre cette " société économe en eau » censée nous sauver. Cet optimisme, peu réaliste au regard des exemples cités, est probablement l'un des principaux reproches à faire à cette analyse socio-économique et culturelle fouillée de la gestion de l'eau. On regrettera également l'enchaînement parfois un peu désordonné des exemples, ainsi que l'utilisation parfois exclusive de sources journalistiques pour décrire ceux-ci. Il est vrai que les sources scientifiques sont souvent rares en ce domaine. 